\title{
Simple sol-gel auto-combustion synthesis and characterization of Lead Hexaferrite by utilizing cherry juice as a novel fuel and green capping agent
}

\author{
Fatemeh Ansari, Masoud Salavati-Niasari* \\ Institute of Nano Science and Nano Technology, University of Kashan, Kashan, P. O. Box. 87317-51167, I. R. \\ Iran. \\ *Corresponding author. Tel. +98 31 55912383; Fax +98 3155913201. \\ E-mail address: $\underline{\text { salavati@kashanu.ac.ir }}$
}

\begin{abstract}
Lead Haxaferrite $\left(\mathrm{PbFe}_{12} \mathrm{O}_{19}\right)$ nanoparticles have been developed by a new way preparing using the sol gel auto combustion route, without adding external surfactant. The present work focused on the synthesis and characterization of $\mathrm{PbFe}_{12} \mathrm{O}_{19}$ nanoparticles at low temperature using Cherry juice as a novel fuel and green capping agent for the first time. The effect of optimum amount of reductant, calcination temperature on the morphology and size of products were investigated. The size and agglomeration of the nanoparticles increase with decreasing Cherry juice content. When the amount of Cherry juice is $20 \mathrm{~mL}$ and calcination temperature is $800{ }^{\circ} \mathrm{C}$, the product is pure and found to be $\mathrm{PbFe}_{12} \mathrm{O}_{19}$ nanoparticles. The products were characterized by $\mathrm{X}$-ray diffraction pattern (XRD), scanning electron microscope (SEM), transmission electron microscopy (TEM), energy dispersive spectrometry (EDS). Furthermore, vibrating sample magnetometer (VSM) was used to study the magnetic properties of $\mathrm{PbFe}_{12} \mathrm{O}_{19}$ samples.

KEYWORDS: Nanostructures; Sol-gel; Auto combustion; Magnetic properties; Natural reductant.
\end{abstract}




\section{Introduction}

Hexagonal ferrites are group of ceramic magnets having large technological applications as permanent magnets, nanoelectromagnetic devices, microwave devices and magnetic recording media [1]. M-type hexagonal ferrites have appeared as novel materials with great technological and scientific interest considering their brilliant physical properties such as dependable magnetization, high coercive force, large magnetocrystalline anisotropy and relatively high Curie temperature, as well as notable chemical stability and low cost.

Among diverse inorganic materials, the hexagonal ferrites with a magnetoplumbite structure and a general formula $\mathrm{MFe}_{12} \mathrm{O}_{19}(\mathrm{M}=\mathrm{Ba}, \mathrm{Sr}, \mathrm{Pb})$ are suitable candidate in chemistry and chemical engineering fields due to their great corrosion resistance and excellent chemical and thermal stability. In particular, the hexagonal ferrites are hard-magnetic magnets with a high saturation magnetization and a high theoretical maximum coercivity, which will profit the chemical process improvement [2-5].

There are numerous approaches to prepare hexagonal ferrites, such as phase inversion [6], electroless plating [7], electro spinning [8], template [9], high-energy ball milling [10], co-precipitation [11], hydrothermal [12], aqueous solution [13], micro-emulsion [14], glass-crystallization [15], salt melt methods [16] and sol-gel approaches [17]. As compared to other approaches, the sol-gel method has been confirmed to be an easy and adaptable method to construct hexagonal ferrites [18]. Different materials, such as metals, metal oxides and ceramics have been synthesized utilizing the sol-gel method $[19,20]$.

It is worthy to understand that properties of the powders depend on their particle size and morphology [21-28]. Consequently, exploring appropriate techniques to prepare ferrites and controlling the morphology and the size of the particles are noteworthy. Here, we extend the sol-gel auto combustion procedure to synthesize lead hexaferrite. This is a unique approach with an exclusive mixture of the chemical sol-gel procedure and the combustion procedure based on the gelling and subsequent combustion of an aqueous solution including salts of 
the desired metals and the capping agent. Nowadays, for increasing biocompatibility and reducung pollution replacement of chemical compound by natural source is important in synthesis process because natural sources are green reagents and eco-friendly materials. The color of pomegranate, blueberry, black rice, cherry and etc., is due to anthocyanin pigments. These pigments which act as anti-oxidant reagent and in chemical reaction can be used as a reducing agent [29-30]. Furthermor anthocyanin pigment has a huge structure, so it can be used as a capping agent in nanomaterials synthesis procedure. In contrast to other works, our approach is clean, suitable, low-cost and eco-friendly practical process for green preparation of lead hexaferrite nanoparticles. This procedure is less complicated than the others. We have prepared lead hexaferrite from metal nitrates and cherry juice as capping agent. To the best of our knowledge, it is the first time that lead hexaferrite nanoparticles are formed at $800{ }^{\circ} \mathrm{C}$ by using cherry juice as novel fuel and capping agent in reactions.

\section{Experimental}

\subsection{Materials and experiments}

All the chemicals used in our experiments, $\mathrm{Fe}\left(\mathrm{NO}_{3}\right)_{3} \cdot 9 \mathrm{H}_{2} \mathrm{O}$ and $\mathrm{Pb}\left(\mathrm{NO}_{3}\right)_{2}$ were of analytical grade, were purchased from Merck and were used as received without further purification. XRD patterns were collected with a diffractometer of Philips Company with X'Pert Promonochromatized $\mathrm{Cu} \mathrm{K}_{\alpha}$ radiation $(\lambda=1.54 \AA$ ). FE-SEM images were obtained on MIRA3 FEG-SEM. TEM images were obtained on a Philips EM208S transmission electron microscope with an accelerating voltage of $100 \mathrm{kV}$. EDS analysis was obtained on Philips EM208. The magnetic properties of the samples were detected at room temperature using a vibrating sample magnetometer (VSM, Meghnatis Kavir Kashan Co., Kashan, Iran).

\subsection{Synthesis of $\mathrm{PbFe}_{12} \mathrm{O}_{19}$ nanoparticles}

The $\mathrm{PbFe}_{12} \mathrm{O}_{19}$ nanoparticles were synthesized by the sol-gel auto combustion route. First, $\mathrm{Pb}\left(\mathrm{NO}_{3}\right)_{2}$ was dissolved in distilled water to form a clear solution. Then, an aqueous solution from different amount of cherry 
juice including: in absence of cherry juice, $10 \mathrm{~mL}, 15 \mathrm{~mL}, 20 \mathrm{~mL}, 25 \mathrm{~mL}$ and $30 \mathrm{~mL}$ was added into the lead nitrate solution drop-wise under strong magnetic stirring at room temperature. The solution was heated by stirring at $60{ }^{\circ} \mathrm{C}$. After stirring the solution for $30 \mathrm{~min}$, an aqueous solution including $\mathrm{Fe}\left(\mathrm{NO}_{3}\right)_{3} \cdot 9 \mathrm{H}_{2} \mathrm{O}$ was added to the above solution and was heated at $120{ }^{\circ} \mathrm{C}$ by stirring for $1 \mathrm{~h}$. The experiments were carried out with molar ratio between $\mathrm{Pb}$ and $\mathrm{Fe}, 1: 6$. Evaporation of the mixed solution affected the formation of a very viscous gel. Then the gel was dried in an oven at $120{ }^{\circ} \mathrm{C}$. The final remain was calcined at diverse temperatures $800{ }^{\circ} \mathrm{C}$ for 2h. Table 1 lists the reaction conditions for the synthesis of $\mathrm{PbFe}_{12} \mathrm{O}_{19}$. This work is compared with the other work in Table 3.

\section{Results and discussion}

Fig. 1a-c shows the XRD patterns of samples were prapered in the presence of $5 \mathrm{~mL}, 10 \mathrm{~mL}$ and $15 \mathrm{~mL}$ cherry juice. When the amount of cherry juice was $5 \mathrm{~mL}$ a mixture of $\mathrm{PbFe}_{4} \mathrm{O}_{7}$ (JCPDS No.09-0048), $\mathrm{PbFe}_{2} \mathrm{O}_{4}$ (JCPDS No. 04-0705) and PbO (JCPDS No. 85-1414) and (JCPDS No. 01-0824) were obtained. In the presence of 10 mL cherry juice $\mathrm{PbFe}_{4} \mathrm{O}_{7}$ (JCPDS No.09-0048) and $\mathrm{PbO}$ (JCPDS No. 01-0824) were synthesized. With increasing the amount of cherry juice to $15 \mathrm{~mL} \mathrm{PbFe}_{12} \mathrm{O}_{19}$ (JCPDS No.17-0660) was formed with impurity of $\mathrm{PbO}$ (JCPDS No.85-1287). Fig. 2a-e illustrate the XRD patterns of as-synthesized hexaferrites. When the amount of cherry juice was $20 \mathrm{~mL}$ and was calcined at $800{ }^{\circ} \mathrm{C}$ (sample no 5), the products had the peaks corresponding to pure hexagonal $\mathrm{PbFe}_{12} \mathrm{O}_{19}$ (JCPDS No. 31-0686) (Fig. 2a). When the cherry juice content increased to $25 \mathrm{~mL}$ (sample no 7), and $30 \mathrm{~mL}$ (sample no 8), a mixture of $\mathrm{PbFe}_{12} \mathrm{O}_{19}, \mathrm{Fe}_{2} \mathrm{O}_{3}$ (Fig. 2b) and only $\mathrm{Fe}_{3} \mathrm{O}_{4}$ (Fig. 2c) were obtained, respectively. Changing of the calcined temperature to $700{ }^{\circ} \mathrm{C}$ and the amount of $20 \mathrm{~mL}$ juice (sample no 6), the products had the peaks corresponding to hexagonal $\mathrm{PbFe}_{12} \mathrm{O}_{19}$ (JCPDS No. 310686) and $\mathrm{Fe}_{2} \mathrm{O}_{3}$ (JCPDS No. 04-0755). (Fig. 2d).Fig. 2e, exhibits XRD pattern of as-synthesized hexaferrites without cherry juice (sample no 1). in absence of cherry juice, only $\mathrm{Fe}_{2} \mathrm{O}_{3}$ was obtained. Therefore, These 
patterns confirm that the minimum of cherry juice content for preparation of $\mathrm{PbFe}_{12} \mathrm{O}_{19}$ is $20 \mathrm{~mL}$ and the calcination temperature of $800{ }^{\circ} \mathrm{C}$ is ideal temperature.

It was found that the existence of impurity peaks is due to the lack or excess of enough cherry juice as fuel and reductant. The ceramic samples were first prepared via the four basic steps: powder preparation, green body forming, sintering and finishing. Powders of $\mathrm{a}-\mathrm{Fe}_{2} \mathrm{O}_{3}$ and $\mathrm{PbO}$ in a $6: 1$ molar ratio were mixed in solvent on the sttirer [32], which at the beginning of the reaction $\mathrm{Pb}$ was reacted because of the potential reduction of less than $\mathrm{Fe}$ and $\mathrm{PbO}$ was formed, when the amount of reductant was low the powders of $\mathrm{PbO}$ and $\mathrm{a}-\mathrm{Fe}_{2} \mathrm{O}_{3}$ were not mixed compeletly and lead hexaferrites formation reaction was not done, with increasing the amount of cherry juice to $20 \mathrm{~mL}$ pure lead haxa ferrites was obtained. Following excess of enough reductant, Intermediate $\mathrm{Fe}_{2} \mathrm{O}_{3}$ was formed and in the presence of $30 \mathrm{~mL}$ cherry juice, $\mathrm{Fe}^{+3}$ was reduced to $\mathrm{Fe}^{+2}$ and $\mathrm{Fe}_{3} \mathrm{O}_{4}$ was synthesized. Therefore for the formation of pure $\mathrm{PbFe}_{12} \mathrm{O}_{19}$ is needed $20 \mathrm{~mL}$ cherry juice.

In continuance, the effect of cherry juice on the morphology of the hexaferrite nanoparticles was considered, while the molar ratio between $\mathrm{Pb} / \mathrm{Fe}$ was chosen to be 1:6. Fig. 3a-d exhibit the SEM images of the hexaferrite nanoparticles achieved with different amount of cherry juice. It can be seen that the size and agglomeration of the nanoparticles decrease through the increasing of the cherry juice content. Fig. $3 \mathrm{~d}$ with the amount of $20 \mathrm{~mL}$ cherry juice has even more distribution than other samples. Fig. $3 \mathrm{f}$ exhibits nanoparticles achieved without the presence of cherry juice. In fact, in absence of cherry juice as green capping agent, serious agglomeration of nanoparticles happened and only $\mathrm{Fe}_{2} \mathrm{O}_{3}$ was obtained (Fig. 3e). Therefore, cherry juice has critical effect on preparation of hexaferrite nanoparticles. The effect of the calcination temperature on the morphology of hexaferrite nanoparticles was considered. By decreasing the temperature from $800{ }^{\circ} \mathrm{C}$ (Fig. 3d) to $700{ }^{\circ} \mathrm{C}$ (Fig. 3e) and the amount $20 \mathrm{~mL}$ cherry juice, the agglomeration of nanoparticles increased and the homogeneity decreased. Therefore, the calcination temperature of $800{ }^{\circ} \mathrm{C}$ is ideal temperature. 
Typical histograms of the particle diameters for the samples Nos. 1, 2, 3, 4, 5 and 6 are seen in Fig. 4a-f, respectively. By comparing the particle size distribution of the products, it is found that $\mathrm{PbFe}_{12} \mathrm{O}_{19}$ prepared in the presence of $20 \mathrm{~mL}$ cherry juice and calcined at $800{ }^{\circ} \mathrm{C}$ has smaller particle size distribution $(15-45 \mathrm{~nm})$. Also, $\mathrm{PbFe}_{12} \mathrm{O}_{19}$ prepared without cherry juice has the largest particle size distribution.

Fig. 4 reveals the TEM images of the hexaferrite achieved at calcination temperature $800{ }^{\circ} \mathrm{C}$ for $2 \mathrm{~h}$ (sample no 5) in various scales. These images exhibit formation of agglomeration of nanoparticles with width ranging nearly $10-15 \mathrm{~nm}$.

Chemical purity and stoichiometry of the $\mathrm{PbFe}_{12} \mathrm{O}_{19}$ were tested by EDS. The strong peaks related to $\mathrm{Fe}$ and $\mathrm{Pb}$ are found in Fig. 5. Moreover, the EDS spectrum of sample no. 5 shows the oxygen that further confirms the formation of $\mathrm{PbFe}_{12} \mathrm{O}_{19}$.

Fig.6 exhibits FT-IR spectrum of as-prepared hexaferrite nanoparticles and reveals two absorption peaks nearly $442 \mathrm{~cm}^{-1}$ and $587 \mathrm{~cm}^{-1}$, corresponding to the $\mathrm{Fe}-\mathrm{O}$ band in hexaferrite. FT-IR spectrum exhibits that the product does not show any strong IR-active peak consistent to impurities.

The hexaferrites are all ferrimagnetic materials, and their magnetic properties are intrinsically linked to their crystalline structures [31]. They all have a magneto crystalline anisotropy, that is the induced magnetization has a preferred orientation within the crystal structure. These materials are divided into two main groups: uniaxial hexaferrites (with an easy axis of magnetization) and ferroxplana or hexaplana ferrites (with an easy plane, or cone, of magnetization) [31]. Fig. 7 shows the magnetization versus applied magnetic field $\left(\mathrm{M}_{-} \mathrm{H}\right)$ curve at 300 $\mathrm{K}$ for the as-synthesized lead hexaferrites (samples no. 5, 6). The hysteresis loops in this figure exhibit a ferromagnetic behavior for the $\mathrm{PbFe}_{12} \mathrm{O}_{19}$ nanostructures. The specific saturation (Ms) and coercivity $(\mathrm{Hc})$ of sample no. 5 and 6 are also obtained from VSM measurement. The specific saturation magnetization and coercivity of sample no 5 (Fig. 6 a) are about $7.6 \mathrm{emu} \mathrm{g}^{-1}$ and 300 Oe respectively. Ms and Hc for sample no 4 (Fig. 6 b) is about $15.2 \mathrm{emu} / \mathrm{g}$ and the coercivity (Hc) of the sample is about $1100 \mathrm{Oe}$, This sample with a high 
$\mathrm{Hc}$ is characterized as a hard ferrite and is appropriate for using permanent magnetic materials. Table 2 compares magnetic hysteresis parameters of samples.

\section{Conclusion}

Lead hexaferrites were synthesized via a simple sol-gel auto combustion route. This approach confirmed a new, simple, green, cost-effective and rapid method. The effect of the various amount of cherry juice and calcination temperature on purity and crystallinity of product was investigated, and it was found that lead hexaferrite nanoparticles are formed at $800{ }^{\circ} \mathrm{C}$ by using cherry juice as novel fuel and green capping agent for the first time. Moreover, concerning the purity of the product, crystallinity, and magnetic properties, this sample is the best one. The obtained product is a hard magnetic material. The specific saturation magnetization and coercivity are $15.2 \mathrm{emu} / \mathrm{g}$ and $1100 \mathrm{Oe}$, respectively.

\section{Acknowledgment}

Authors are grateful to the council of Iran National Science Foundation (91053846) and University of Kashan for supporting this work by Grant No (159271/1021). 


\section{References}

[1] I. Zavislyak, M. Popov, G. Srinivasan, A cut-off millimeter wave resonator technique for mapping magnetic parameters in hexagonal ferrites, Measurement Science and Technology, 20 (2009) 115704.

[2] F. Song, X. Shen, M. Liu, J. Xiang, Formation and characterization of magnetic barium ferrite hollow fibers with high specific surface area via sol-gel process, Solid state sciences, 12 (2010) 1603-1607.

[3] S.-G. Kim, W.-N. Wang, T. Iwaki, A. Yabuki, K. Okuyama, Low-temperature crystallization of barium ferrite nanoparticles by a sodium citrate-aided synthetic process, The Journal of Physical Chemistry C, 111 (2007) 10175-10180.

[4] P. Xu, X. Han, M. Wang, Synthesis and magnetic properties of $\mathrm{BaFe}_{12} \mathrm{O}_{19}$ hexaferrite nanoparticles by a reverse microemulsion technique, The Journal of Physical Chemistry C, 111 (2007) 5866-5870.

[5] I.P. Parkin, G. Elwin, L.F. Barquin, Q.T. Bui, Q.A. Pankhurst, A.V. Komarov, Y.G. Morozov, Self-Propagating High Temperature Synthesis of Hexagonal Ferrites MFe12O19 (M= Sr, Ba), Advanced Materials, 9 (1997) 643-645.

[6] A. Leo, S. Liu, J.C.D. da Costa, The enhancement of oxygen flux on Ba $0.5 \mathrm{Sr} 0.5$ Co $0.8 \mathrm{Fe} 0.2 \mathrm{O} 3-\delta$ (BSCF) hollow fibers using silver surface modification, Journal of Membrane Science, 340 (2009) 148-153.

[7] M. Jean, V. Nachbaur, J. Bran, J.-M. Le Breton, Synthesis and characterization of $\mathrm{SrFe}_{12} \mathrm{O}_{19}$ powder obtained by hydrothermal process, Journal of Alloys and compounds, 496 (2010) 306-312.

[8] J.-W. Yi, S.-B. Lee, J.-B. Kim, S.-K. Lee, Fabrication of ultrafine hollow Ni and Ni/Fe fibers and their dispersion characteristics in the epoxy matrix, Surface and Coatings Technology, 204 (2010) 1419-1425.

[9] H. Lu, L. Zhang, W. Xing, H. Wang, N. Xu, Preparation of $\mathrm{TiO}_{2}$ hollow fibers using poly (vinylidene fluoride) hollow fiber microfiltration membrane as a template, Materials Chemistry and Physics, 94 (2005) 322327. 
[10] S. Zhan, D. Chen, X. Jiao, S. Liu, Facile fabrication of long $\alpha$-Fe $2 \mathrm{O} 3, \alpha-\mathrm{Fe}$ and $\gamma-\mathrm{Fe}_{2} \mathrm{O}_{3}$ hollow fibers using sol-gel combined co-electrospinning technology, Journal of colloid and interface science, 308 (2007) 265270.

[11] D. Repetto, A. Enders, K. Kern, Coupled perpendicular magnetization in $\mathrm{Fe} / \mathrm{Cu} / \mathrm{Fe}$ trilayers, Journal of magnetism and magnetic materials, 300 (2006) 479-483.

[12] M. Rashad, I. Ibrahim, A novel approach for synthesis of M-type hexaferrites nanopowders via the coprecipitation method, Journal of Materials Science: Materials in Electronics, 22 (2011) 1796-1803.

[13] D. Primc, M. Drofenik, D. Makovec, Low-Temperature Hydrothermal Synthesis of Ultrafine Strontium Hexaferrite Nanoparticles, European Journal of Inorganic Chemistry, 2011 (2011) 3802-3809.

[14] A. Drmota, M. Drofenik, A. Žnidaršič, Synthesis and characterization of nano-crystalline strontium hexaferrite using the co-precipitation and microemulsion methods with nitrate precursors, Ceramics International, 38 (2012) 973-979.

[15] D. Zaitsev, S. Kushnir, P. Kazin, Y.D. Tretyakov, M. Jansen, Preparation of the $\mathrm{SrFe}_{12} \mathrm{O}_{19}$-based magnetic composites via boron oxide glass devitrification, Journal of magnetism and magnetic materials, 301 (2006) 489494.

[16] R. Arendt, Liquid-phase sintering of magnetically isotropic and anise by the reaction of $\mathrm{BaFe}_{2} \mathrm{O}_{4}$ with $\mathrm{Fe}_{2} \mathrm{O}_{3}$, J Solid State Chem, 8 (1973) 339.

[17] C. Gong, D. Chen, X. Jiao, Q. Wang, Continuous hollow $\alpha-\mathrm{Fe}_{2} \mathrm{O}_{3}$ and $\alpha$-Fe fibers prepared by the sol-gel method, Journal of Materials Chemistry, 12 (2002) 1844-1847.

[18] J.D. Mackenzie, D.R. Ulrich, Ultrastructure processing of advanced ceramics, Wiley New York1988.

[19] F. Ansari, F. Soofivand, M. Salavati-Niasari, Utilizing maleic acid as a novel fuel for synthesis of $\mathrm{PbFe}_{12} \mathrm{O}_{19}$ nanoceramics via sol-gel auto-combustion route, Materials Characterization, 103 (2015) 11-17. 
[20] F. Ansari, A. Sobhani, M. Salavati-Niasari, Sol-gel auto-combustion synthesis of $\mathrm{PbFe}_{12} \mathrm{O}_{19}$ using maltose as a novel reductant, RSC Adv., 4 (2014) 63946-63950.

[21] F. Ansari, A. Sobhani, M. Salavati-Niasari, Facile synthesis, characterization and magnetic property of $\mathrm{CuFe}_{12} \mathrm{O}_{19}$ nanostructures via a sol-gel auto-combustion process, Journal of Magnetism and Magnetic Materials, 401 (2016) 362-369.

[22] S. Mandizadeh, M. Bazarganipour, M. Salavati-Niasari, A low-cost and eco-friendly viable approach for green synthesis of barium haxaferrite nanostructures using palm oil, Ceramics International, 40 (2014) 1568515691.

[23] M. Ghaed-Amini, M. Bazarganipour, M. Salavati-Niasari, Calcium molybdate octahedral nanostructures, hierarchical self-assemblies controllable synthesis by coprecipitation method: Characterization and optical properties, Journal of Industrial and Engineering Chemistry, 21 (2015) 1089-1097.

[24] S. Gholamrezaei, M. Salavati-Niasari, M. Bazarganipour, M. Panahi-Kalamuei, S. Bagheri, Novel precursors for synthesis of dendrite-like PbTe nanostructures and investigation of photoluminescence behavior, Advanced Powder Technology, 25 (2014) 1585-1592.

[25] Z. Shahri, M. Bazarganipour, M. Salavati-Niasari, Controllable synthesis of novel zinc molybdate rod-like nanostructures via simple surfactant-free precipitation route, Superlattices and Microstructures, 63 (2013) 258266.

[26] M. Jafari, A. Sobhani, M. Salavati-Niasari, Effect of preparation conditions on synthesis of Ag 2 Se nanoparticles by simple sonochemical method assisted by thiourea, Journal of Industrial and Engineering Chemistry, 20 (2014) 3775-3779.

[27] M. Esmaeili-Zare, M. Salavati-Niasari, A. Sobhani, Sonochemical synthesis of HgSe nanoparticles: Effect of metal salt, reaction time and reductant agent, Journal of Industrial and Engineering Chemistry, 20 (2014) 3518-3523. 
[28] M. Salavati-Niasari, B. Shoshtari-Yeganeh, M. Bazarganipour, Facile synthesis of rod-shape nanostructures lead selenide via hydrothermal process, Superlattices and Microstructures, 58 (2013) 20-30.

[29] F. Tavakoli, M. Salavati-Niasari, F. Mohandes, Green synthesis and characterization of graphene nanosheets, Materials Research Bulletin, 63 (2015) 51-57.

[30] F. Tavakoli, M. Salavati-Niasari, F. Mohandes, Green synthesis of flower-like CuI microstructures composed of trigonal nanostructures using pomegranate juice, Materials Letters, 100 (2013) 133-136.

[31] R.C. Pullar, Hexagonal ferrites: a review of the synthesis, properties and applications of hexaferrite ceramics, Progress in Materials Science, 57 (2012) 1191-1334.

[32] S.A. Palomares-Sa'nchez, S. Di'az-Castaño'n, S. Ponce-Castañeda, M. Mirabal-Garcı'a, F. Leccabue, B.E. Watts, Materials Letters, 59 (2005) 591- 594

[34] S. Dõaz-Castan8o, J.L. Sanchez L, E. Estevez-Rams, F. Leccabue, B.E. Watts, Journal of Magnetism and Magnetic Materials, 185 (1998) 194Đ198.

[35] F. Ansari, F. Soofivand, M. Salavati-Niasari, Materials Characterization, 103 (2015) 11-17 


\section{Figure captions}

Fig 1. XRD patterns of the products synthesized in the presence of different amounts of cherry juice: (a) $5 \mathrm{~mL}$ (sample no. 2), (b) $10 \mathrm{~mL}$ (sample no. 3) and (c) $15 \mathrm{~mL}$ (sample no. 4).

Fig. 2. XRD patterns of lead hexaferrites prepared from $\mathrm{Pb}\left(\mathrm{NO}_{3}\right)_{2}$ and $\mathrm{Fe}\left(\mathrm{NO}_{3}\right)_{3} \cdot 9 \mathrm{H}_{2} \mathrm{O}$ at calcinations temperature $800^{\circ} \mathrm{C}$ for $2 \mathrm{~h}$, with different amount of cherry juice: (a) $20 \mathrm{~mL}$ (sample no. 5), (b) $25 \mathrm{~mL}$ (sample no. 7), (c) $30 \mathrm{~mL}$ (sample no. 8), (d) $700{ }^{\circ} \mathrm{C}$ for $2 \mathrm{~h}$ and $20 \mathrm{ml}$ cherry juice (sample no. 6) and (e) without cherry juice (sample no. 1).

Fig. 3. SEM images of $\mathrm{PbFe}_{12} \mathrm{O}_{19}$ of (a) sample no. 2, (b) sample no. 3, (c) sample no. 4, (d) sample no. 5, (e) sample no. 6 and (f) SEM images of sample obtained in the absence of cherry jouce (sample no. 1).

Fig 4. Particle size distribution of samples Nos. (a) 1, (b) 2, (c) 3, (d) 4, (e) 5 and (f) 6.

Fig. 5. TEM images of lead hexaferrite (sample no. 5).

Fig. 6. EDS spectrum of sample no. 5.

Fig. 7. FT-IR spectrum of sample no. 5.

Fig. 8. Magnetization versus applied magnetic field at room temperature for the pure $\mathrm{PbFe}_{12} \mathrm{O}_{19}$ (sample no. 5, 6).

Table 1. The reaction conditions of lead hexaferrites synthesized in this work. 


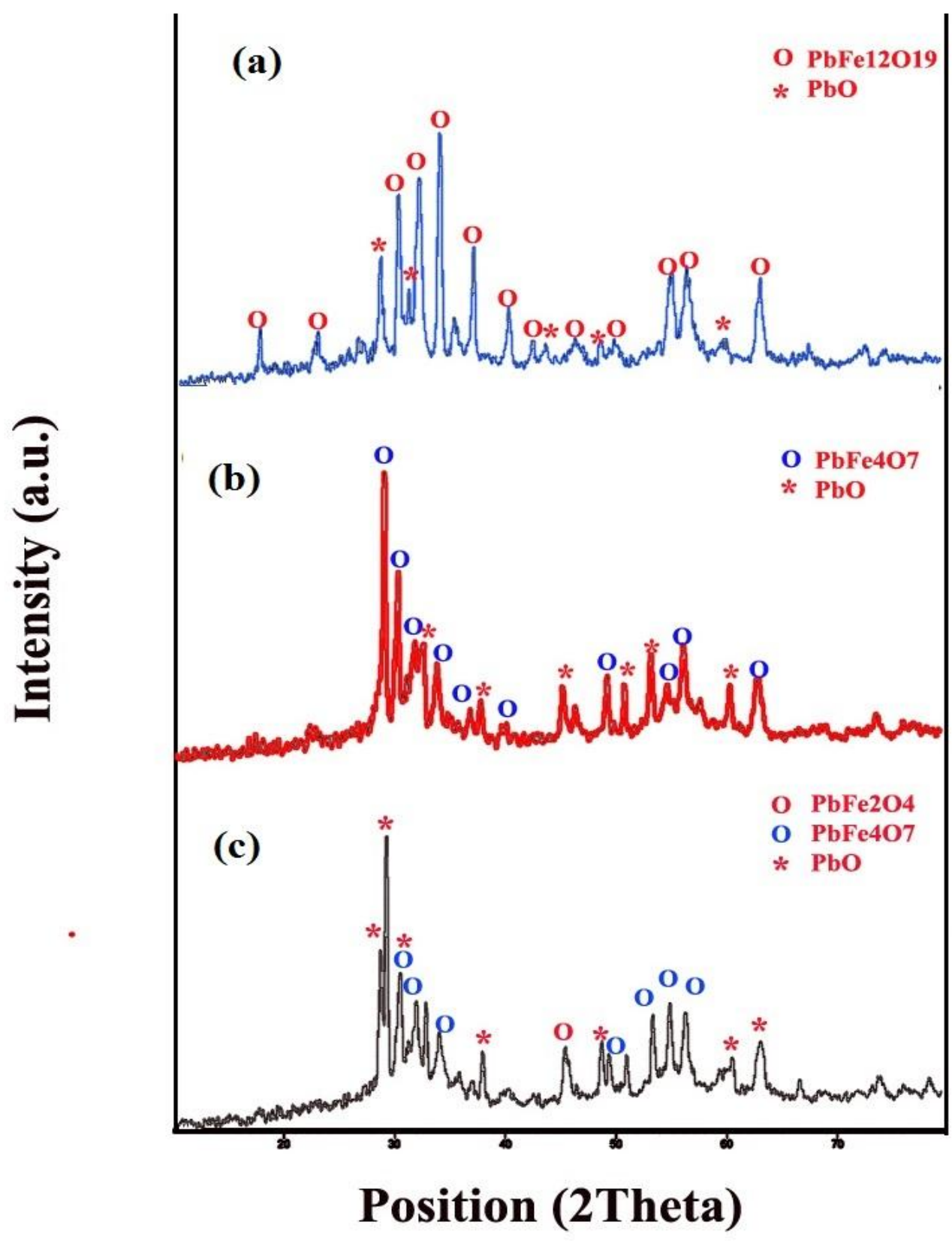

Fig 1. 


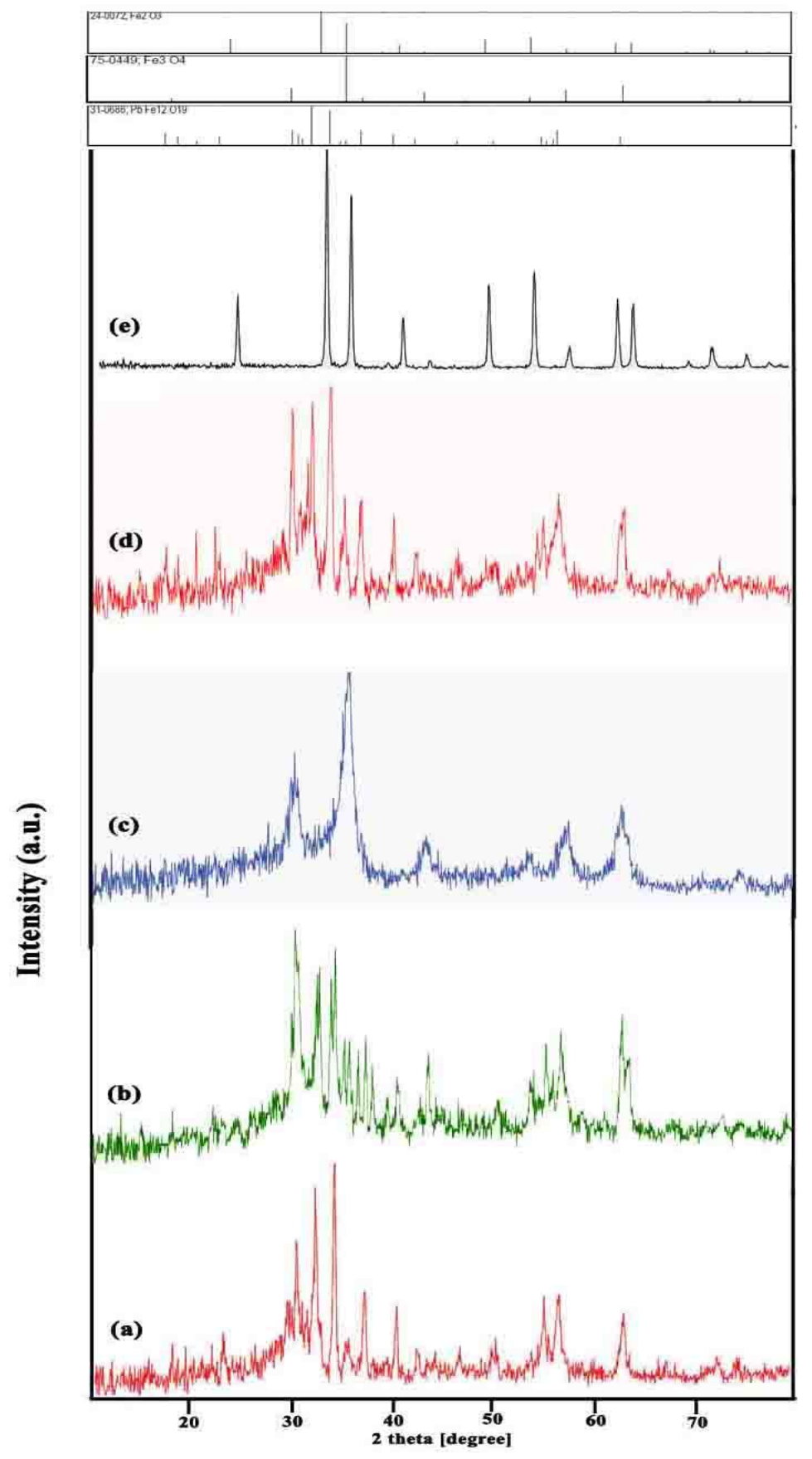

Fig 2. 

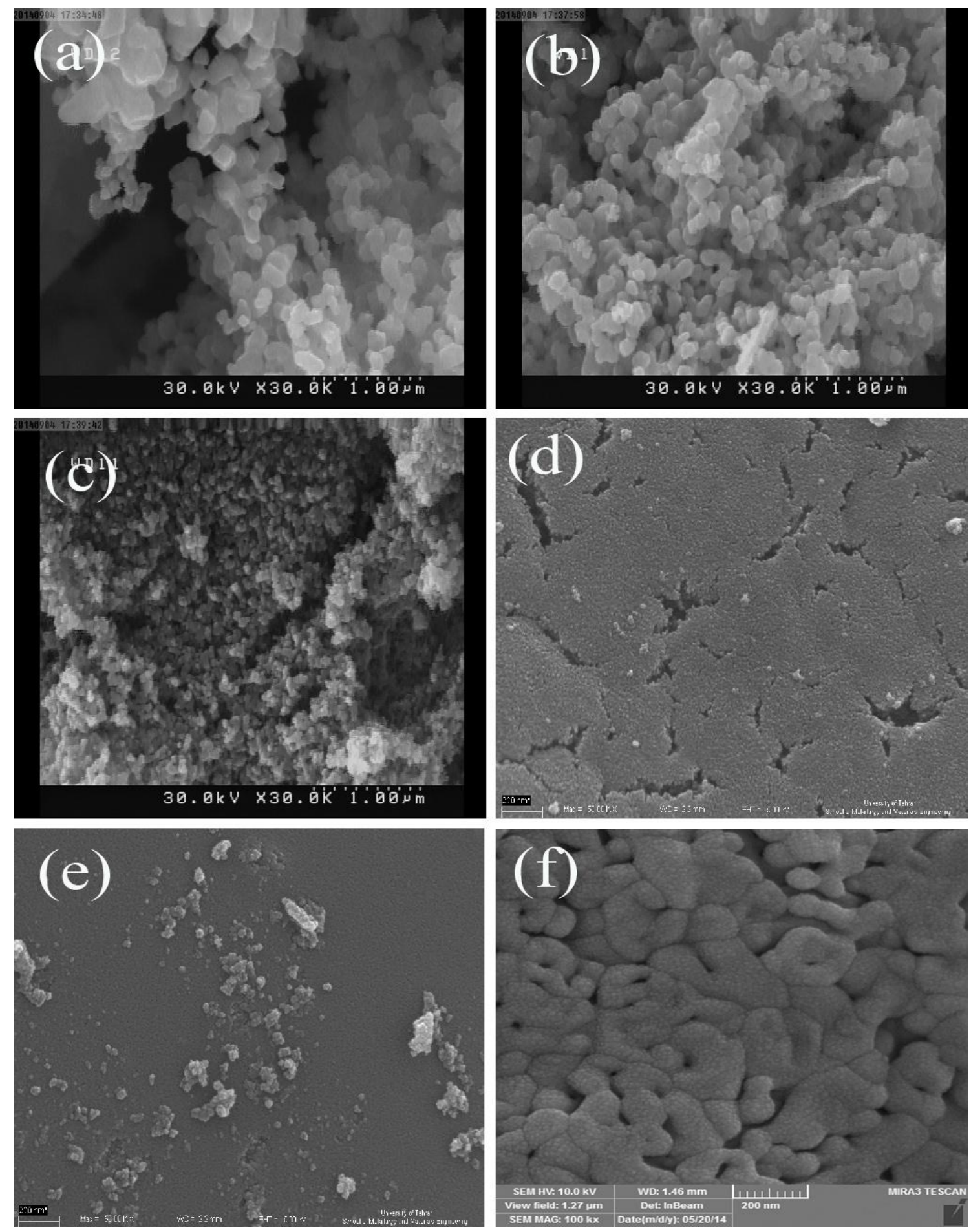

Fig. 3. 


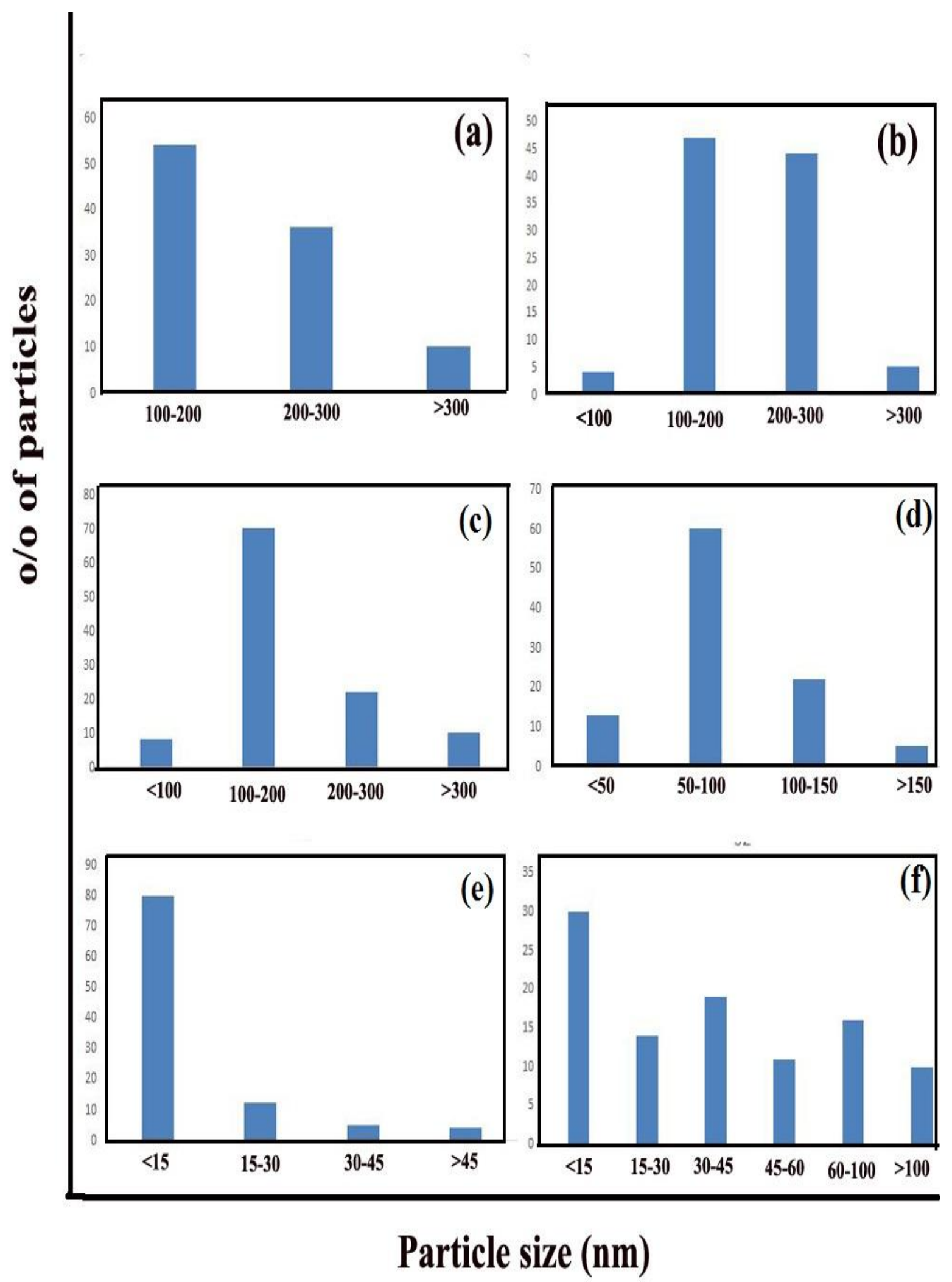

Fig 4. 


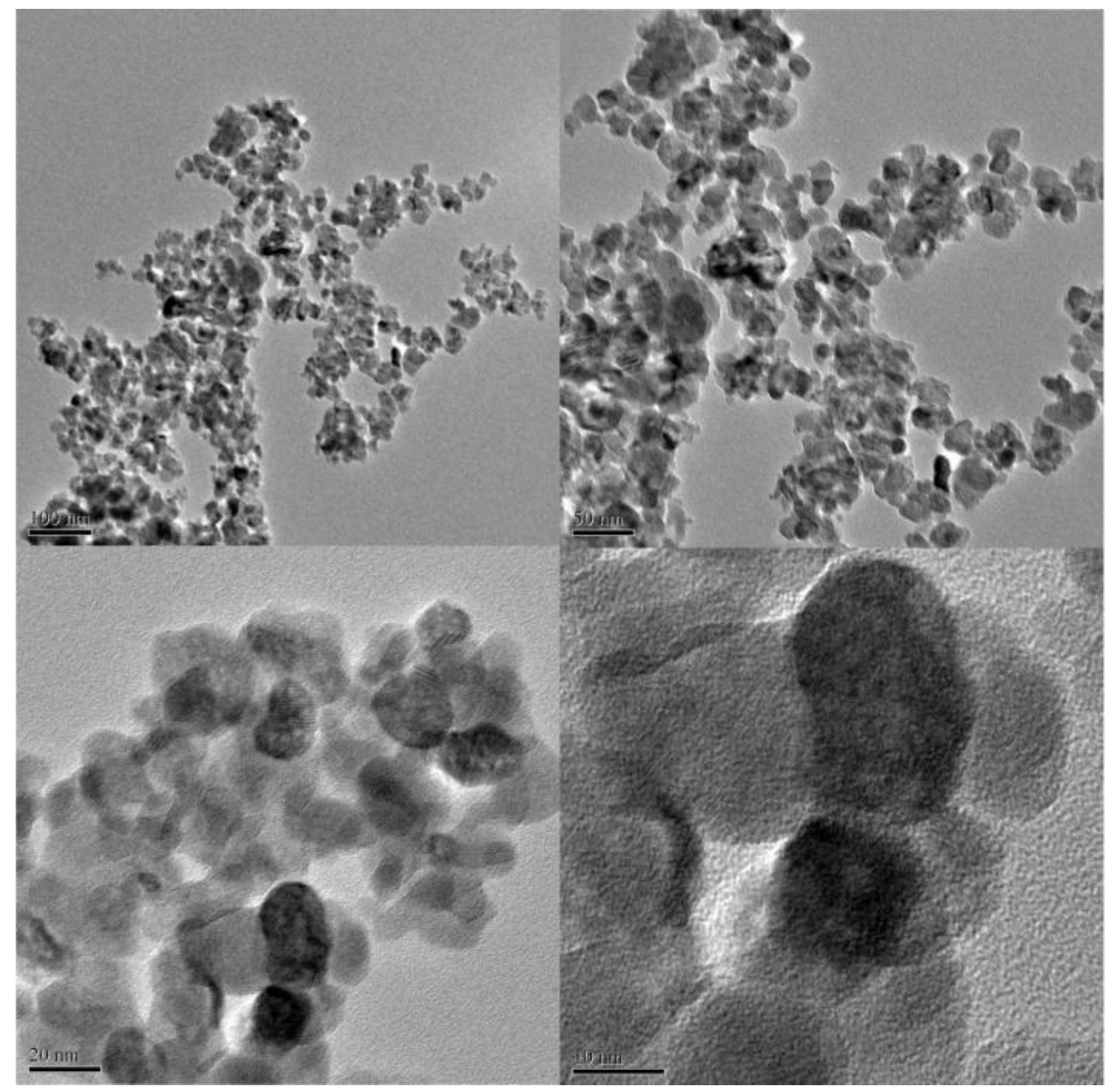

Fig. 5. 


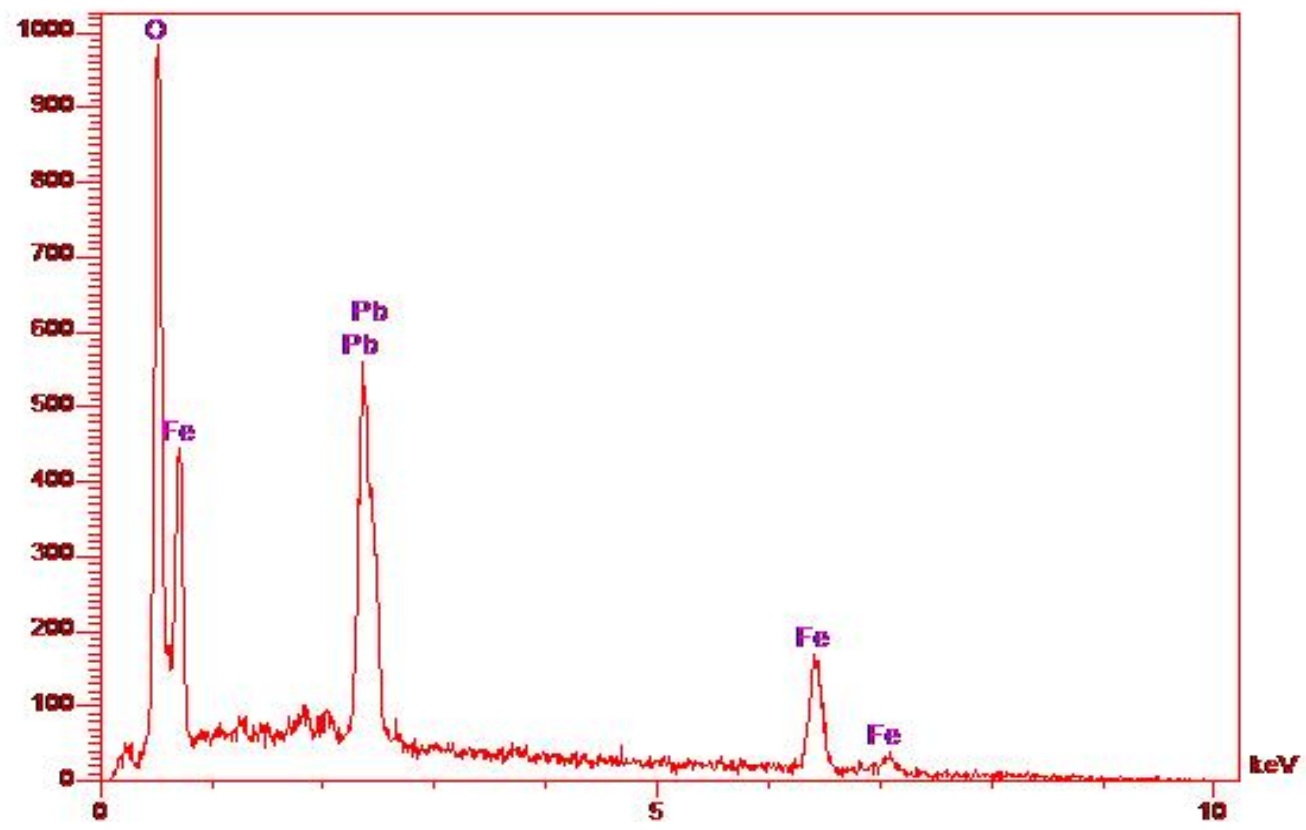

Fig. 6. 


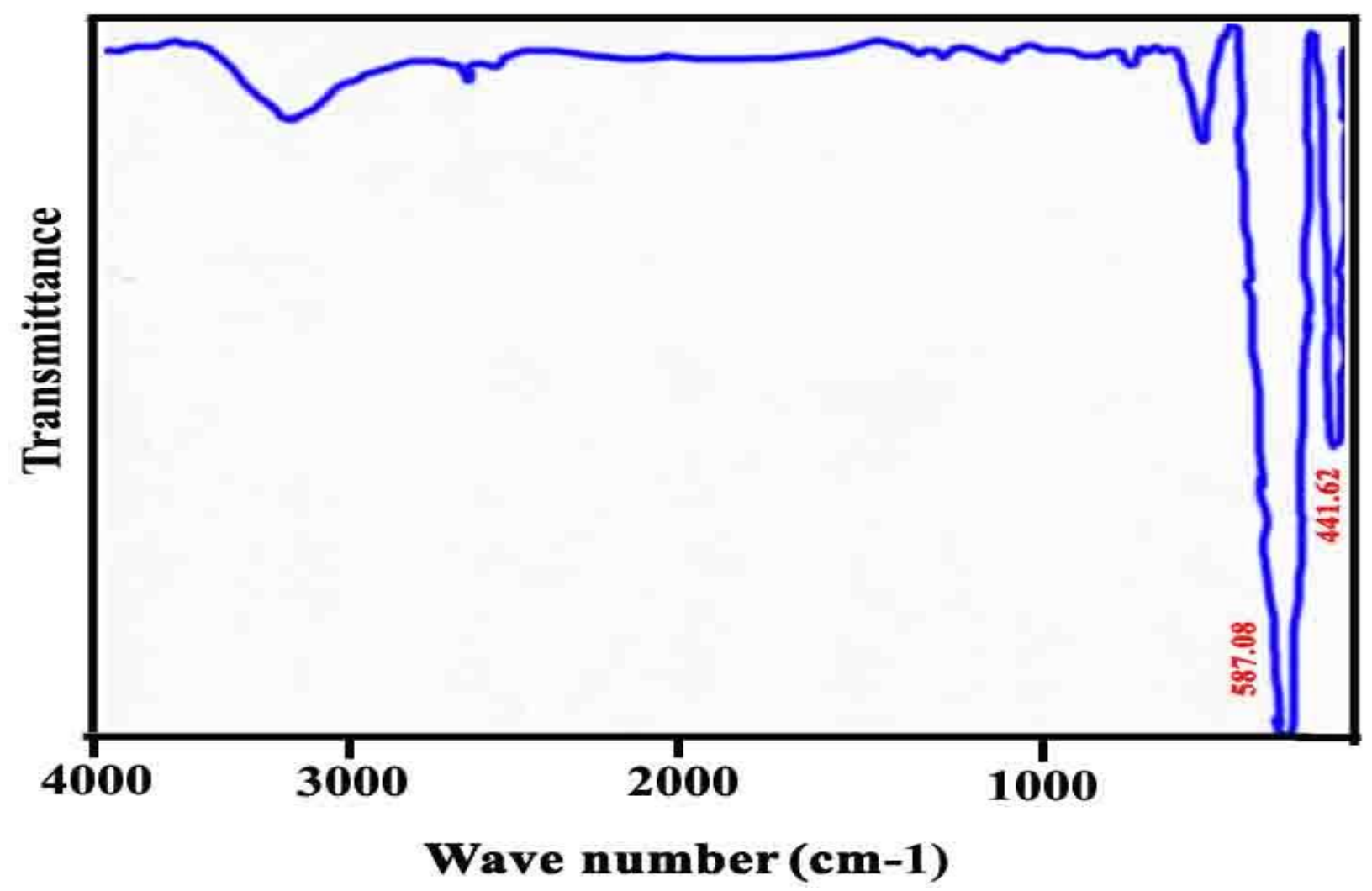

Fig. 7 

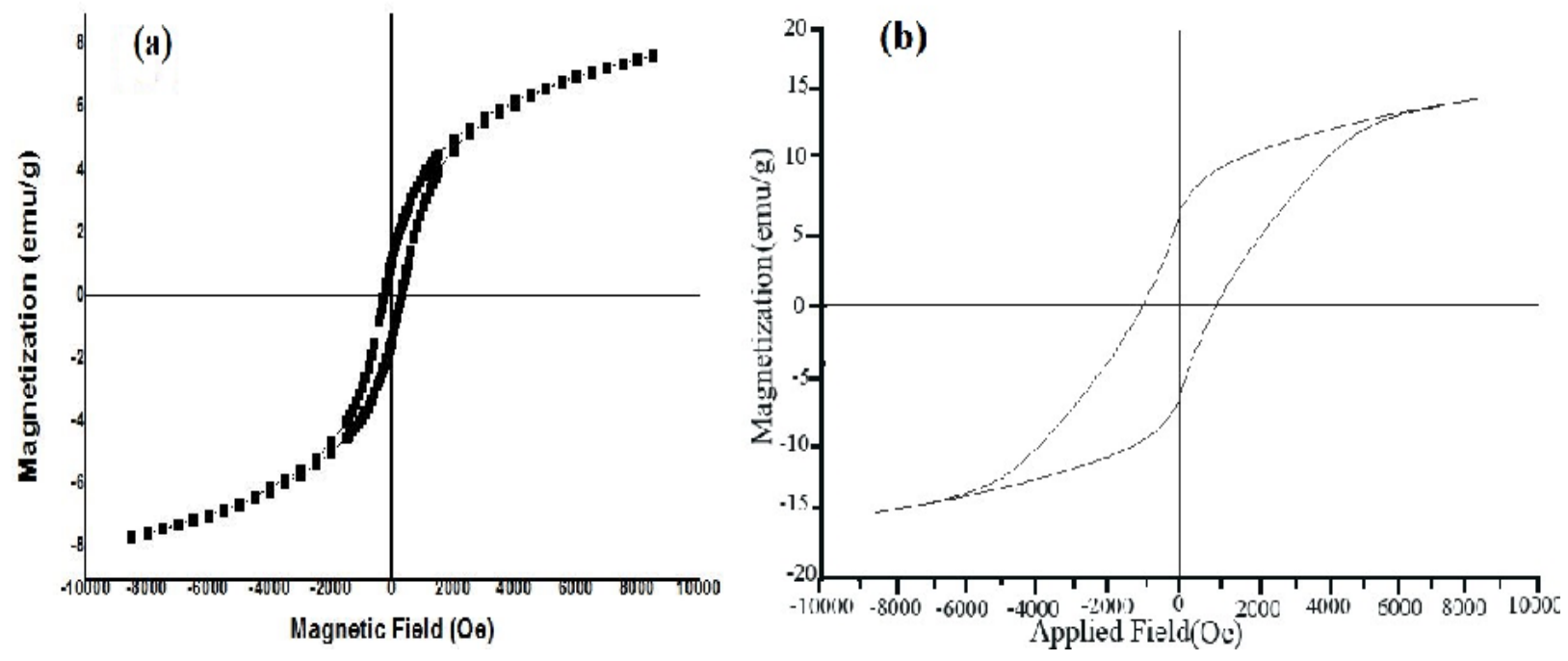

Fig. 8 


\begin{tabular}{|c|c|c|c|c|c|c|}
\hline Sample no & $\begin{array}{l}\text { Amount of } \\
\text { Reductant }\end{array}$ & $\begin{array}{l}\text { Calcination } \\
\text { Temperature } \\
\left({ }^{\mathrm{O}} \mathrm{C}\right)\end{array}$ & $\begin{array}{l}\text { Calcination } \\
\text { Time (min) }\end{array}$ & $\begin{array}{l}\text { Particles size } \\
(\mathrm{SEM})(\mathrm{nm})\end{array}$ & Product & Crystal phase \\
\hline 1 & - & 800 & 120 & 320 & $\mathrm{Fe}_{2} \mathrm{O}_{3}$ & Hexagonal \\
\hline 2 & $5 \mathrm{~mL}$ & 800 & 120 & 240 & $\begin{array}{l}\mathrm{PbO} \text { and } \\
\mathrm{PbFe}_{4} \mathrm{O}_{7}\end{array}$ & \\
\hline 3 & $10 \mathrm{~mL}$ & 800 & 120 & 170 & $\begin{array}{c}\mathrm{PbO}, \mathrm{PbFe}_{2} \mathrm{O}_{4}, \\
\mathrm{PbFe}_{4} \mathrm{O}_{7}\end{array}$ & \\
\hline 4 & $15 \mathrm{ml}$ & 800 & 120 & 110 & $\mathrm{PbFe}_{12} \mathrm{O}_{19}, \mathrm{PbO}$ & \\
\hline 5 & $20 \mathrm{ml}$ & 800 & 120 & 15 & $\mathrm{PbFe}_{12} \mathrm{O}_{19}$ & Hexagonal \\
\hline 6 & $20 \mathrm{ml}$ & 700 & 120 & 22 & $\mathrm{PbFe}_{12} \mathrm{O}_{19}$ & Hexagonal \\
\hline 7 & $25 \mathrm{ml}$ & 800 & 120 & - & $\mathrm{PbFe}_{12} \mathrm{O}_{19}, \mathrm{Fe}_{2} \mathrm{O}_{3}$ & \\
\hline 8 & $30 \mathrm{ml}$ & 800 & 120 & - & $\mathrm{Fe}_{3} \mathrm{O}_{4}$ & \\
\hline
\end{tabular}


Table 2.

\begin{tabular}{cccc}
\hline Sample no. & $\mathrm{M}_{\mathrm{r}}(\mathrm{emu} / \mathrm{g})$ & $\mathrm{M}_{\mathrm{s}}(\mathrm{emu} / \mathrm{g})$ & $\mathrm{H}_{\mathrm{c}}(\mathrm{Oe})$ \\
\hline 5 & 6.69 & 15.20 & 1100.90 \\
\hline 6 & & & \\
\hline & 1.90 & & 300 \\
\hline
\end{tabular}


Table 3.

\begin{tabular}{clcc}
\hline Calcined temprature & Reductant & Particle size (nm) & Refrence No \\
\hline $\mathbf{9 0 0}{ }^{\circ} \mathbf{C}$. & Citric acid & $150-400$ & 33 \\
$920{ }^{\circ} \mathbf{C}$ & $\mathrm{NaOH} / \mathrm{Na} 2 \mathrm{CO} 3$ & 500 & 20 \\
$900{ }^{\circ} \mathbf{C}$ & Maltose & $200-400$ & 35 \\
$900{ }^{\circ} \mathbf{C}$ & Maleic acid & $200-500$ & \\
\hline
\end{tabular}



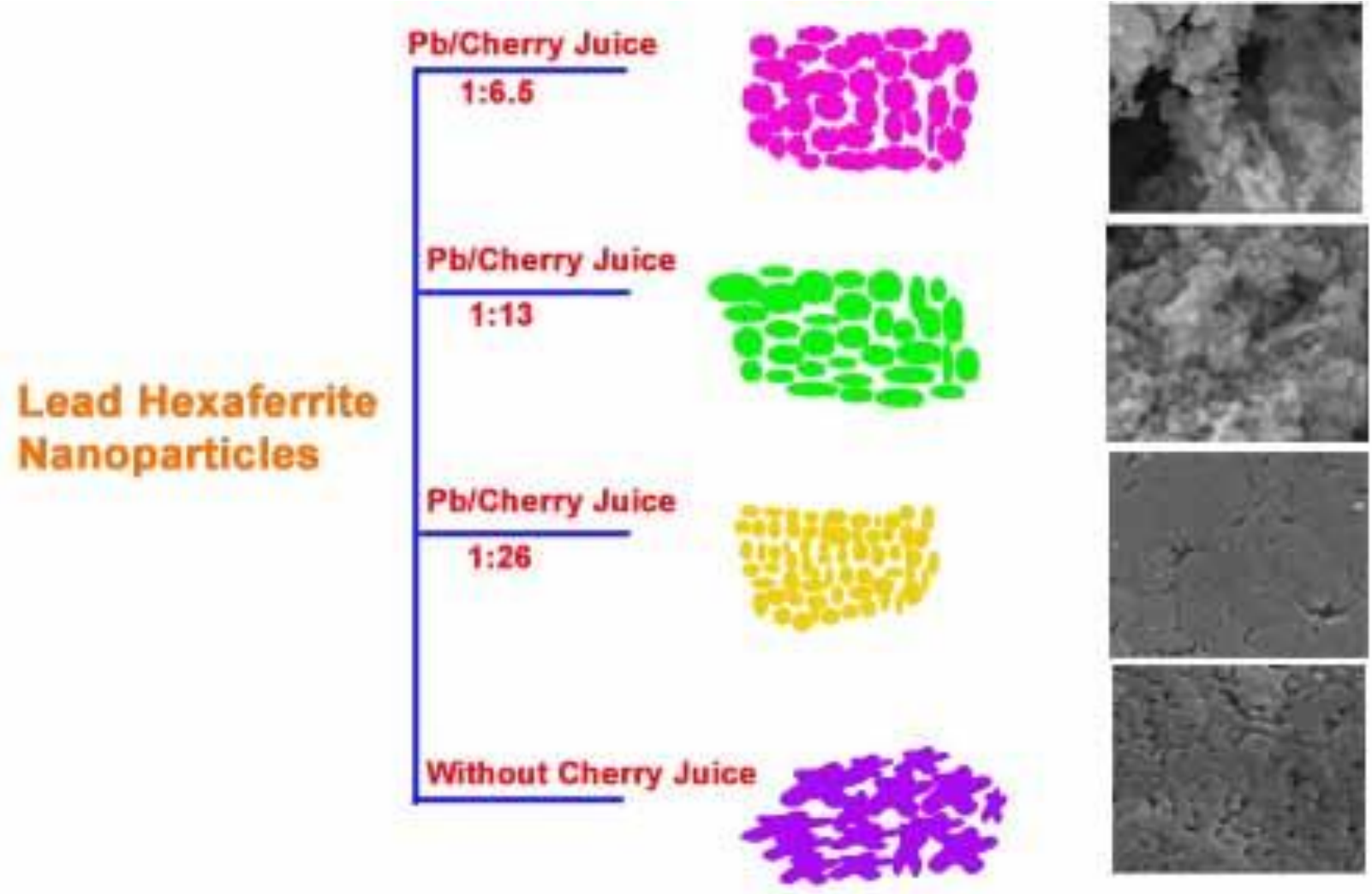